\title{
Health Outcomes of Population-Based Pharmacy Outreach to Increase Statin Use for Prevention of Cardiovascular Disease in Patients with Diabetes
}

\author{
David Grembowski, PhD; James D. Ralston, MD, MPH; and Melissa L. Anderson, MS
}

\begin{abstract}
BACKGROUND: In 2003, Group Health implemented a pharmacy-based, systemwide outreach effort to increase the preventive use of statins and angiotensin-converting enzyme inhibitors in enrollees at risk for cardiovascular disease, including all enrollees with diabetes.

OBJECTIVE: To estimate the associations between the use of statins and major vascular events and the total costs in 2006-2010 for enrollees with diabetes, using a pharmacy-based, systemwide outreach.

METHODS: In a 14-year (1997-2010) longitudinal cohort study design, the study population consisted of 6,975 Group Health enrollees with type 1 or type 2 diabetes, who were enrolled continuously and had no statin use before the Group Health outreach in 1997-2002. Health outcomes were allcause mortality, cardiovascular mortality, myocardial infarction, and stroke. Statin exposure was measured by cumulative statin use since 2003, weighted by the effect of the statin type and dose on the lowering of low-density lipoprotein levels. Regression models estimated associations between cumulative statin use, health outcomes, and total costs in 2006-2010.
\end{abstract}

RESULTS: Among enrollees with no statin use before outreach began in 2003 , about half had no or low exposure to statins by the end of 2005. In 2006-2010, cumulative statin use was greater among enrollees with risk factors for cardiovascular disease. Greater statin use was related to lower cardiovascular deaths and incidence of stroke and myocardial infarction, greater but nonsignificant all-cause mortality, and unrelated to total costs.

CONCLUSIONS: Population-based pharmacy outreach increased statin use for eligible enrollees with diabetes, which was related to better cardiovascular outcomes. Generally, statin use was unrelated to all-cause mortality and total costs.

J Manag Care Spec Pharm. 2016;22(8):909-17

Copyright $\odot 2016$, Academy of Managed Care Pharmacy. All rights reserved.

\section{What is already known about this subject}

Most deaths among patients with diabetes are a result of cardiovascular disease.

Randomized controlled trials show that statins prevent macrovascular events and mortality compared with placebo in patients with diabetes.

Statins are underutilized in patients with diabetes.

\section{What this study adds}

In a large health care organization, a population-based pharmacy outreach increased statin use for primary and secondary prevention in patients with diabetes.

Statin use was greater among patients with risk factors for cardiovascular disease.

Pharmacy outreach, when combined with electronic medical record alerts and prepopulated order sets for statins, may lead to greater statin use and better cardiovascular outcomes but may not contribute to changes in all-cause mortality and total costs.

$\mathrm{M}$ ost deaths among patients with diabetes are a result of cardiovascular disease, so reducing macrovascular disease progression and mortality through medication treatment is an important element of diabetes care. ${ }^{1}$ The 2002 Heart Protection Study (HPS) and the 2004 Collaborative Atorvastatin Diabetes Study are the major randomized controlled trials showing benefits of statins (HMG-CoA reductase inhibitors) compared with placebo for the prevention of macrovascular events in patients with diabetes. ${ }^{2-5}$

In response to evidence from the HPS, Group Health, a health care system in the state of Washington, implemented a pharmacy-based, systemwide outreach effort in 2003-2005 to increase statin and angiotensin-converting enzyme inhibitor (ACEI) use among patients at risk for cardiovascular disease, including patients with diabetes. The program expanded statin use beyond treatment guidelines. In 2002-2004, the American Diabetes Association (ADA) recommended statins only when lifestyle modifications did not achieve lipid goals. ${ }^{6-8}$ In 2005, the ADA recommended statins for adults aged over 40 years with a total cholesterol $>135 \mathrm{mg} / \mathrm{dL}^{9}{ }^{9}$ In 2004 , Brown et al. and Saydah et al. reported that statins were underutilized in patients with diabetes. ${ }^{1,10}$

This study takes advantage of quality improvements at Group Health to close information gaps regarding the potential health benefits of increasing statins on a population level for a cohort of patients with diabetes. In a systematic review and meta-analysis of quality improvement strategies in diabetes care for hemoglobin Alc (Alc), low-density lipoprotein (LDL) cholesterol, and blood pressure reported in 94 randomized 
trials and 48 cluster-randomized trials, studies that intervened in the entire health system, versus individual patients or providers, had the largest effects on outcomes, which suggested that the Group Health pharmacy outreach might improve diabetes management and health outcomes. ${ }^{11}$ The ADA currently recommends organized, system-level approaches to optimal diabetes management, but there is substantial room for improvement-in some studies, only about half of the patients with diabetes had a total cholesterol $<200 \mathrm{mg} / \mathrm{dL} .^{12,13}$ Less than continuous use of statins in patients with diabetes is common, which is associated with worse treatment outcomes and greater costs. . $^{14,15}$

Following the rollout of the Group Health pharmacy outreach in 2003-2005, the purpose of this study was to examine the associations between the use of statins and major vascular events and costs in 2006-2010.

\section{Methods}

\section{Group Health Pharmacy Outreach Program}

Similar to previous studies, statin and ACEI use at Group Health was relatively low in eligible enrollees with diabetes, according to evidence at the turn of the twenty-first century. In 2001-2002, about 30\% of the Group Health study population with type 1 or type 2 diabetes were prescribed statins, while ACEI use was almost $60 \%$.

In February 2003, motivated by the 2002 HPS findings, ${ }^{2}$ Group Health identified eligible patients for statin and ACEI use from automated pharmacy data, diabetes disease registry data, and diagnostic data. Pharmacists called eligible patients to inform them of their eligibility for statins and ACEIs and initiated orders when appropriate. In September 2004, Group Health also began spreading clinical decision support tools in the EpicCare electronic medical record (EMR) across clinics, including EMR alerts and prepopulated order sets for statins and ACEIs. Implementation of these tools was complete across all clinics by August 2005. The alerts were designed to (a) remind providers to prescribe statins and ACEIs in qualifying patients with diabetes and (b) allow an easy mechanism for ordering the right statins and ACEIs at the right dose and with appropriate laboratory monitoring. The alerts appeared to providers in 2 formats depending on whether the patient had an existing diagnosis of coronary artery disease or diabetes or was receiving a new diagnosis of coronary artery disease or diabetes. By 2005, patients who should have been taking ACEIs but had an intolerance to the drug were being prescribed angiotensin II receptor blockers (ARBs) as an alternative therapy.

\section{Population and Study Design}

Patients involved in this study were from Group Health, a mixedmodel health care system with over 580,000 enrollees and a multispecialty group practice of 800 physicians who work in its owned and operated facilities. The patient population consisted of 14,489 patients continuously enrolled from 1997 through 2010, alive in the first quarter of 2006, had diabetes before January 1, 2006, were on the Group Health diabetes registry, and obtained care in the western Washington group practice. To enter the registry, enrollees met at least 1 of the following criteria in the previous 12 months: (a) filled prescriptions for insulin or an oral hypoglycemic agent; (b) had $1 \mathrm{Alc}>7.0$; (c) had 2 or more fasting plasma glucose levels $>126 \mathrm{mg} / \mathrm{dL}$; (d) had 2 or more random plasma glucose levels $>200 \mathrm{mg} / \mathrm{dL}$; (e) had any combination of 2 fasting plasma glucose and random plasma glucose over the previous limits; or (f) had 2 outpatient diagnoses of diabetes or any inpatient diagnoses of diabetes. Enrollees with only a history of gestational diabetes were not eligible.

If competing risks of mortality existed, estimates of the relative contributions of statins to health outcomes may be biased. Therefore, we identified and excluded enrollees with residual comorbid conditions (other than hypertension, coronary artery disease, congestive heart failure, and chronic obstructive pulmonary disease) that were present at baseline (2005) and that may have been predictive of death in 2006-2010. Enrollees with the following 4 nonmutually exclusive, residual comorbid conditions were excluded using the Deyo version of the Charlson Comorbidity Index, ${ }^{16}$ a validated index predicting the likelihood of mortality based on 17 comorbid disorders: (1) moderate-to-severe liver disease, (2) malignancy (including leukemia and lymphoma), (3) metastatic solid tumor, and (4) acquired immune deficiency syndrome. Enrollees with endstage renal disease at baseline (2005) also were excluded in the analysis. Following these exclusions, the remaining sample size was 11,845 enrollees.

This sample of 11,845 enrollees were divided into the following 3 mutually exclusive groups:

1. Statin users before the start date of the Group Health pharmacy outreach ( $n=3,778$, "pre-outreach group")

2. First-time statin users after the start date of the Group Health pharmacy outreach ( $n=6,975$, "post-outreach group")

3. Those who never used statins in 1997-2010 ( $n=1,092$ enrollees with a bimodal age distribution of younger and much older adults)

This study's objective was performed using a 1997-2010 longitudinal cohort study design with the 6,975 post-outreach enrollees. Study protocols were approved by the Group Health Human Subjects Review Committee.

\section{Measures and Data Sources}

Health Outcomes and Costs. Four health outcomes were measured: all-cause mortality, cardiovascular mortality, cerebrovascular accident (stroke), and myocardial infarction. ${ }^{2,3}$ All-cause mortality in 1997-2010 was measured using date of death in the Group Health Death Register. The original source of data in the death register is the Washington State Death Certificate System 
Health Outcomes of Population-Based Pharmacy Outreach to Increase Statin Use

for Prevention of Cardiovascular Disease in Patients with Diabetes

TABLE 1 Statin and LDL Cholesterol Reduction

\begin{tabular}{l|c|c|c|c|c|c}
\hline \% LDL Reduction ${ }^{41-43}$ & Atorvastatin & Fluvastatin & Lovastatin & Pravastatin & Rosuvastatin & Simvastatin \\
\hline $22^{42}$ & & $20 \mathrm{mg}$ & $10 \mathrm{mg}$ & $10 \mathrm{mg}$ & $5 \mathrm{mg}$ \\
\hline 30 & & $40 \mathrm{mg}$ & $20 \mathrm{mg}$ & $20 \mathrm{mg}$ & $10 \mathrm{mg}$ \\
\hline 34 & $10 \mathrm{mg}$ & $80 \mathrm{mg}$ & $40 \mathrm{mg}$ & $40 \mathrm{mg}$ & $20 \mathrm{mg}$ \\
\hline 42 & $20 \mathrm{mg}$ & & $80 \mathrm{mg}$ & $80 \mathrm{mg}$ & $5 \mathrm{mg} 10 \mathrm{mg}$ & $40 \mathrm{mg}$ \\
\hline 50 & $40 \mathrm{mg}$ & & & & $80 \mathrm{mg}$ \\
\hline 68 & $80 \mathrm{mg}$ & & & & $20 \mathrm{mg}$ & $40 \mathrm{mg}$ \\
\hline
\end{tabular}

$L D L=$ low-density lipoprotein

in the Washington State Department of Health. Cardiovascular mortality was measured from death register data using coding algorithms in Coleman et al. (2013) ${ }^{17}$; the algorithms were correlated highly with causes of death determined by case review. Cardiovascular deaths included deaths attributed to coronary artery disease, peripheral vascular disease, and stroke.

From Group Health records, we measured whether enrollees had a stroke or myocardial infarction (MI) during study followup. We created measures indicating whether an enrollee had prevalent MI or stroke at baseline (diagnosis in 1997-2005) and a separate variable for MI or stroke during follow-up (20062010). MI was defined as a hospitalization with International Classification of Diseases, Ninth Revision, Clinical Modification (ICD-9-CM) code 410.xx (excluding 410.x2, which indicated readmission/follow-up to the initial episode) and a length of stay (LOS) between 3 and 180 days, or death if LOS $<3$ days. ${ }^{18,19}$ Stroke was defined by ICD-9-CM codes 431, 433, 434, and $436 .{ }^{20}$

Cost was a secondary outcome, and the source of cost information was the Group Health Cost Management $\&$ Information System, where each unique patient encounter regardless of setting was assigned a relative value unit-driven cost. Costs for services from providers outside Group Health were Group Health's claims-based payment to those providers. For each enrollee, quarterly total costs were measured in 2005-2010.

Medication Use. Prescription information existed for all study years in the Group Health automated information systems and included product name, the number of tablets, prescription date, prescribed daily tablets, drug dosage, and duration of the prescription.

To define statin use, we used dose equivalency, or standard daily dose (SDD), according to the Oregon State University review of the literature on the impact of different doses of statins on the lowering of LDL, supplemented by the University of Michigan's review of statin equivalency and the STELLAR Trial. The SDD approach allows conversion of different medications based on therapeutic effect (such as percentage of LDL reduction), which are combined into a single exposure measure. In contrast to traditional measures of adherence, which focus on the proportion of a prescribed medication taken by an enrollee within a time window, the SDD is a combination of duration and the intensity of statin use. This measure was chosen because the intensity of statins, not just adherence, has been associated with cardiovascular outcomes. The cumulative exposure to statins, measured by SDD, was calculated in 2 steps. First, the number of tablets dispensed was multiplied by the proportion of LDL reduction (Table 1). The resulting SDD was then distributed equally across the time (days) until next fill or 90 days, whichever was earlier. For example, a prescription for 60 tablets of a statin with 50\% LDL reduction consisted of $30(60 \times 0.50)$ SDDs. If the next statin prescription fill is 45 days later, then the 30 SDDs are distributed across these 45 days until the next fill, resulting in a computed exposure of 0.67 SDD per day (30 SDD/45 days) during that time period. Second, these computed daily doses were summed into a cumulative statin exposure for the calendar quarter.

ACEI/ARB use was calculated using a similar method but was defined relative to the defined daily dose (DDD), or the average maintenance dose per day for a drug taken by adults for the main indication, based on guidance from the World Health Organization. ${ }^{21}$ The total SDD of a prescription of ACEI/ ARB was defined as the number of tablets dispensed, multiplied by the drug strength, then divided by the DDD to obtain the number of SDDs (or DDDs) of drug exposure dispensed. Daily doses were calculated based on fill data and summed to obtain quarterly exposure.

The statin and ACEI/ARB exposures used in this analysis were the cumulative exposure up to any given quarter (sum of all previous quarters in the time series). These continuous measures were recoded to form ordinal categories of cumulative drug use as follows: statin categories: $\leq 120,121-240,241-360$, >360; ACEI/ARB categories: > 700, 701-1,400, 1,401-2,100, $>2,100$. To construct the statin categories, we computed the average and median SDD scores per quarter, which was about 30 (average 31; median 29.9). We multiplied the quarterly score times 4 to measure average annual statin use $(30 \times 4=120)$, which defined the interval increments of the 4 statin categories. A similar protocol was followed for ACEI/ARB categories. 


\section{Health Outcomes of Population-Based Pharmacy Outreach to Increase Statin Use for Prevention of Cardiovascular Disease in Patients with Diabetes}
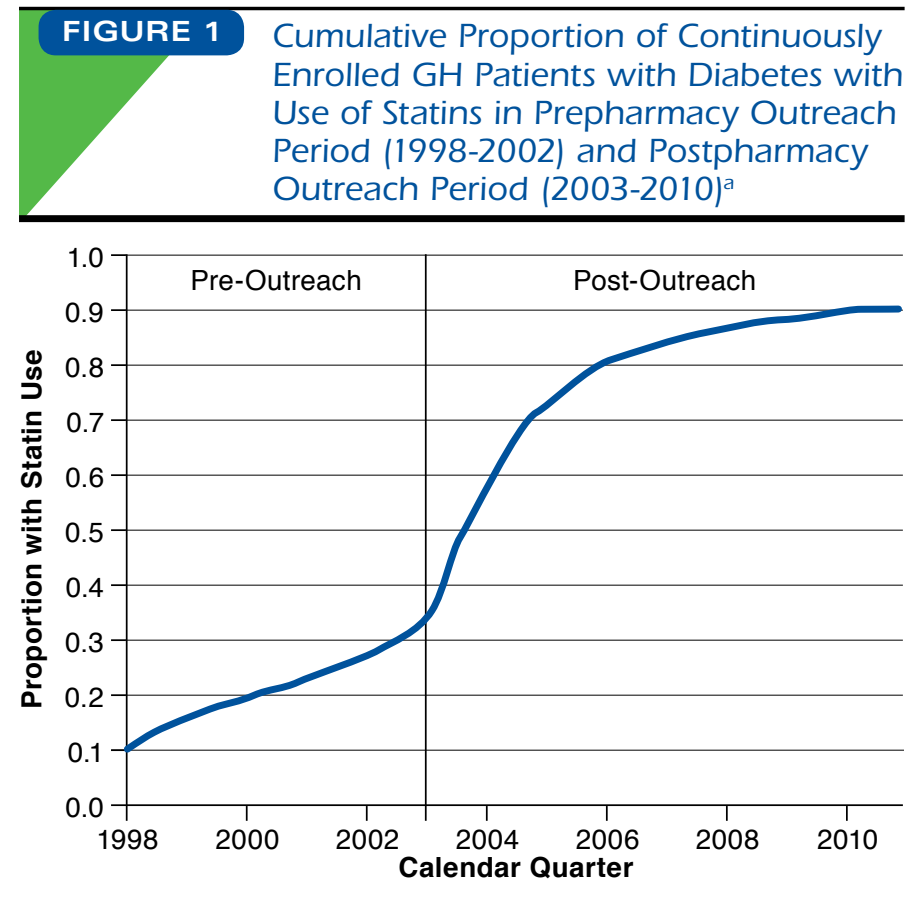

${ }^{a}$ Continuously enrolled GH patients $=11,845$.

GH= Group Health.

Related Care. We also measured whether enrollees received other treatments and medications from 1997 to 2005 that might influence health outcomes in 2006-2010. We constructed yes/no indicators for 3 medical treatments (thrombolysis for cerebrovascular accident, percutaneous coronary angioplasty, and coronary artery bypass grafting), along with 4 medications (clopidogrel, aspirin/extended release dipyridamole, ticlopidine, and cilostazol). ${ }^{22}$

Diabetes. Diabetes duration and treatment were measured quarterly. Diabetes duration since 1993 was measured using the Diabetes Registry, which Group Health established in 1993. Diabetes treatment was measured as insulin, oral hypoglycemics alone, or diet alone. Diabetes management was measured by Alc.

Diabetes Comorbid Conditions and Complications. Common comorbid conditions of diabetes that are related to health outcomes were also measured. ${ }^{23}$ The common comorbid conditions were time-varying measures assessed at baseline (2005) and quarterly from 2006 to 2010 for the following conditions: hypertension, coronary artery disease (CAD), and congestive heart failure $(\mathrm{CHF})$. Because of the chronicity of hypertension, $\mathrm{CAD}$, and $\mathrm{CHF}$, we assumed that after condition onset, the condition persisted for the remainder of the time series. We also measured atrial fibrillation. Chronic pulmonary disease (CPD) was measured using the Charlson index because CPD was common in enrollees; other studies reported that CPD was related to mortality ${ }^{16,24}$; and statin use in CPD patients was related to lower mortality. ${ }^{25}$ The following diabetes complications also were measured: nephropathy, neuropathy, peripheral vascular disease, and retinopathy. ${ }^{20}$

Characteristics. Enrollee characteristics included age and gender.

\section{Statistical Analysis}

Enrollee-quarters were the unit of analysis. Descriptive statistics were computed for enrollee measures at baseline (2005) and the use of treatments and medications from 1997 to 2005 with possible heart and vascular benefits. Cross-tabulations were computed to examine enrollee characteristics by category of cumulative statin use at baseline.

Cox proportional hazards models were used to estimate the association of statin use and each health outcome in 20062010. We estimated 2 multivariate models for statin use and all-cause mortality; all measures were time-varying except gender. In the first, or primary model, we estimated the relative contribution of statins to all-cause mortality, adjusting for the following confounders not likely to be mediators of the relationship between statins and mortality: age, gender, diabetes duration, diabetes treatment, hypertension, CPD, and atrial fibrillation. The second model contained all the variables in the first model plus indicators for whether the enrollee had CAD, CHF, stroke, or MI in 1997-2005. Much of the beneficial impact of statins on all-cause mortality was hypothesized to be through the lowering of LDL, ${ }^{26,27}$ and LDL lowering was incorporated into the SDD measure of statin exposure. Therefore, we did not include LDL in the regression model because LDL was, at least partially, in the causal pathway between statins and mortality, so including LDL would result in overadjustment or an assessment of the impact of statin on mortality independent of LDL level. A similar protocol was followed for the other health outcomes. Enrollees who died but had missing cause of death $(n=120)$ were excluded from the analysis of cardiovascular deaths, and those with prevalent MI $(n=198)$ and stroke $(n=243)$ at baseline were excluded from the corresponding analyses of incident MI and stroke.

To estimate the association between statin use and total costs, we used a repeated measures generalized estimating equation model with an independence working correlation structure and robust standard errors to account for correlated observations (calendar quarters) by enrollee. We fit the cost model with a log link and gamma errors to estimate cost ratios. Cost models adjusted for the same set of covariates as the models for health outcomes. All regression models were estimated with Stata version 12 software (StataCorp, College Station, TX). 


\section{Health Outcomes of Population-Based Pharmacy Outreach to Increase Statin Use for Prevention of Cardiovascular Disease in Patients with Diabetes}

TABLE 2 Baseline Characteristics of Post-Outreach Enrollees, by Cumulative Statin Exposure at Baseline (2005)

\begin{tabular}{|c|c|c|c|c|c|c|}
\hline \multirow[b]{3}{*}{ Age, mean [SD] } & & \multicolumn{5}{|c|}{ Baseline Cumulative Statin Exposure Categories } \\
\hline & $\begin{array}{c}\text { Total } \\
\mathrm{N}=6,975 \\
\mathrm{n}(\%)\end{array}$ & $\begin{array}{c}\text { None } \\
\mathrm{n}=1,231 \\
\%\end{array}$ & $\begin{array}{c}1-120 \\
\mathrm{n}=2,252 \\
\%\end{array}$ & $\begin{array}{c}121-240 \\
\mathrm{n}=1,785 \\
\%\end{array}$ & $\begin{array}{c}241-360 \\
\mathrm{n}=1,487 \\
\%\end{array}$ & $\begin{array}{c}>360 \\
\mathrm{n}=220 \\
\%\end{array}$ \\
\hline & $\begin{array}{ll}64.5 & {[12.0]} \\
\end{array}$ & $\begin{array}{ll}57.0 & {[12.6]}\end{array}$ & $\begin{array}{ll}64.6 & {[12.1]}\end{array}$ & $\begin{array}{ll}66.5 & {[10.9]}\end{array}$ & $\begin{array}{ll}67.8 & {[10.1]}\end{array}$ & $\begin{array}{ll}67.1 & {[10.2]}\end{array}$ \\
\hline \multicolumn{7}{|l|}{ Age, category } \\
\hline$<50$ years & $661 \quad(9.5)$ & 28.4 & 8.5 & 4.4 & 2.6 & 1.8 \\
\hline 50 to $<60$ years & $2,180 \quad(31.3)$ & 42.5 & 32.9 & 28.9 & 22.7 & 29.6 \\
\hline 60 to $<70$ years & $1,870 \quad(26.8)$ & 12.2 & 25.9 & 30.8 & 35.2 & 29.1 \\
\hline 70 to $<80$ years & $1,357 \quad(19.5)$ & 8.4 & 19.1 & 21.1 & 26.0 & 27.3 \\
\hline $80+$ years & $907 \quad(13.0)$ & 8.5 & 13.6 & 14.9 & 13.6 & 12.3 \\
\hline Male & $3,322 \quad(47.6)$ & 47.2 & 45.1 & 49.6 & 50.0 & 43.6 \\
\hline Hypertension & $2,570 \quad(36.9)$ & 24.1 & 39.1 & 38.3 & 41.6 & 41.4 \\
\hline Coronary artery disease & $392 \quad(5.6)$ & 1.8 & 5.0 & 5.8 & 8.6 & 11.8 \\
\hline Congestive heart failure & $81 \quad(1.2)$ & 0.7 & 1.4 & 1.3 & 1.1 & 0.9 \\
\hline Chronic pulmonary disease & $2,506 \quad(35.9)$ & 35.8 & 37.6 & 35.0 & 34.8 & 35.0 \\
\hline Stroke & $243 \quad(3.5)$ & 1.0 & 3.5 & 4.5 & 4.1 & 5.0 \\
\hline Myocardial infarction & $198 \quad(2.8)$ & 0.7 & 2.1 & 3.7 & 4.3 & 5.5 \\
\hline Atrial fibrillation & $594 \quad(8.5)$ & 4.6 & 8.4 & 8.9 & 11.0 & 12.3 \\
\hline Charlson score, mean [SD] & $1.41 \quad[0.96]$ & $1.13[0.84]$ & $1.48 \quad[0.97]$ & $1.43 \quad[0.99]$ & $1.50 \quad[0.96]$ & $\begin{array}{ll}1.56 & {[1.02]}\end{array}$ \\
\hline \multicolumn{7}{|l|}{ Diabetes complications } \\
\hline Nephropathy & $708 \quad(10.2)$ & 7.6 & 10.2 & 10.4 & 11.5 & 13.2 \\
\hline Neuropathy & $746 \quad(10.7)$ & 7.5 & 10.5 & 11.2 & 12.9 & 12.3 \\
\hline Peripheral vascular disease & $192 \quad(2.8)$ & 1.8 & 3.2 & 2.6 & 3.1 & 2.7 \\
\hline Retinopathy & $404 \quad(5.8)$ & 4.4 & 5.6 & 5.5 & 7.0 & 10.5 \\
\hline \multicolumn{7}{|l|}{ Diabetes treatment intensity } \\
\hline Diet alone & $2,308 \quad(33.1)$ & 42.2 & 40.0 & 28.5 & 21.7 & 21.4 \\
\hline Oral hypoglycemics & $3,107 \quad(44.5)$ & 39.9 & 38.4 & 47.3 & 49.8 & 45.9 \\
\hline Insulin & $1,560 \quad(22.4)$ & 18.0 & 20.6 & 24.2 & 28.6 & 32.7 \\
\hline \multicolumn{7}{|l|}{ Duration of diabetes } \\
\hline$<1$ year & $677 \quad(9.7)$ & 17.4 & 16.4 & 3.4 & 1.8 & 2.7 \\
\hline 1 to $<2$ years & $519 \quad(7.4)$ & 8.4 & 7.9 & 11.2 & 2.1 & 4.1 \\
\hline 2 to $<3$ years & $497 \quad(7.1)$ & 6.4 & 6.3 & 7.7 & 7.7 & 11.4 \\
\hline 3 to $<5$ years & $952 \quad(13.7)$ & 15.0 & 13.4 & 13.6 & 13.0 & 14.1 \\
\hline 5 to $<10$ years & $1,994 \quad(28.6)$ & 28.2 & 26.9 & 27.6 & 32.9 & 27.7 \\
\hline $10+$ years & $2,336 \quad(33.5)$ & 24.7 & 29.2 & 36.6 & 42.6 & 40.0 \\
\hline \multicolumn{7}{|l|}{ ACEI/ARB use } \\
\hline \multicolumn{7}{|l|}{ Cumulative at baseline } \\
\hline 700 or less & $2,775 \quad(39.8)$ & 64.0 & 51.8 & 30.0 & 16.8 & 15.9 \\
\hline 701 to 1,400 & $978 \quad(14.0)$ & 9.7 & 11.9 & 18.3 & 15.5 & 15.0 \\
\hline 1,401 to 2,100 & $661 \quad(9.5)$ & 6.9 & 7.7 & 10.3 & 13.1 & 11.4 \\
\hline$>2,100$ & $2,561 \quad(36.7)$ & 19.4 & 28.6 & 41.4 & 54.6 & 57.7 \\
\hline
\end{tabular}

\section{Results}

$\overline{\text { For the 11,845 eligible enrollees with diabetes, after pharmacy }}$ outreach began in 2003, statin use more than doubled from about $35 \%$ in 2003 to about $80 \%$ in 2006 and reached $90 \%$ in 2010 (Figure 1). ACEI/ARB use increased from about 65\% to $85 \%$. In the United States, statin use in people with diabetes increased from $44 \%$ in 2003-2006 to $52 \%$ in 2007-2010, indicating that the large increase in Group Health statin use is likely a result of pharmacy outreach and secular trends. ${ }^{28}$
For the 6,975 first-time statin users after pharmacy outreach began, Table 2 presents the characteristics of enrollees in 2005 (baseline) and shows enrollee characteristics by the 5 categories of cumulative statin exposure at baseline. Average age was 65 years, and there were slightly more females than males. Over $60 \%$ of the enrollees had diabetes for 5 or more years. Less than $11 \%$ had retinopathy, nephropathy, neuropathy, or peripheral vascular disease. Less than $10 \%$ of the enrollees had CAD, CHF, a previous MI or stroke, or atrial fibrillation. 


\section{Health Outcomes of Population-Based Pharmacy Outreach to Increase Statin Use for Prevention of Cardiovascular Disease in Patients with Diabetes}

\begin{tabular}{l|rl}
\hline TABLE 3 & $\begin{array}{l}\text { Baseline Percentage (January 1, 2006) } \\
\text { of Post-Outreach Enrollees Who } \\
\text { Received Treatments and Medications } \\
\text { with Possible Heart and Vascular } \\
\text { Benefits, 1997-2005 }\end{array}$ \\
\hline & $\begin{array}{c}\text { Post-Outreach Enrollees } \\
\mathbf{n}=\mathbf{6 , 9 7 5}\end{array}$ \\
\hline & $\mathbf{n}(\%)$ \\
\hline Thrombolysis for cerebrovascular accident & 12 & $(0.2)$ \\
\hline Percutaneous coronary angioplasty & 188 & $(2.7)$ \\
\hline Coronary artery bypass grafting & 143 & $(2.1)$ \\
\hline Clopidogrel & 171 & $(2.5)$ \\
\hline Aspirin/extended release dipyridamole & 137 & $(2.0)$ \\
\hline Ticlopidine & 2 & $(0.0)$ \\
\hline Cilostazol & 1 & $(0.0)$ \\
\hline
\end{tabular}

About 36\% of enrollees had hypertension or CPD. Oral hypoglycemics were the most common treatment. ACEI/ARB use was bimodal, with $40 \%$ having no or low use versus $37 \%$ in the highest use category. In 2005, the average total cost of care was $\$ 7,209$ (standard deviation $[\mathrm{SD}]=\$ 15,661$; median $=\$ 3,152$ ).

At the beginning of the pharmacy outreach in 2003, enrollees in the post-outreach group had no statin use; by 2005, half of the enrollees $(1,231+2,252=3,483)$ had no or low exposure to statins. In general, statin use was greater among enrollees with greater risk factors for morbidity and mortality. In 2005 (baseline date), those enrollees with greater cumulative statin use were older and had diabetes longer; had more prevalent diabetes complications; had hypertension, CAD, CHF, and greater Charlson comorbidity scores; had a higher baseline prevalence of previous MI, stroke, or atrial fibrillation; and were more likely to be taking insulin. Enrollees who had greater statin use generally had greater ACEI/ARB use as well. In 2005, Alc scores averaged 7.7 [SD = 1.5], and average Alc scores were similar across the 5 categories of cumulative statin exposure (range $=7.6-7.8$ ).

Table 3 shows the percentage of enrollees with previous exposure to nonstatin treatments and medications received in 1997-2005 that may have heart and vascular benefits. Less than $3 \%$ of enrollees received any of the treatments and medications.

Table 4 presents associations between cumulative statin use and health outcomes. All-cause mortality was about $11 \%$, and cardiovascular mortality was about 3\%. In the primary model, compared with enrollees with no or low statin use (cumulative statin $\leq 120$ ), enrollees with greater statin use had higher allcause mortality, but this relationship had borderline statistical significance after controlling for stroke, MI, CAD, and CHF at baseline. The HPS reported that the relative benefit of statin use was similar in younger versus older populations. ${ }^{2}$ We reestimated the all-cause mortality regression model excluding enrollees aged under 55 years and found point estimates nearly identical to those in Table 4. In contrast, enrollees with greater

\begin{tabular}{|c|c|c|}
\hline TABLE 4 & $\begin{array}{l}\text { ciations Betwe } \\
\text { and Health Ou }\end{array}$ & $\begin{array}{l}\text { Cumulative Statin } \\
\text { mes, 2006-2010 }\end{array}$ \\
\hline Statin Use & $\begin{array}{c}\text { Model 1a } \\
\text { HR }(95 \% \text { CI })\end{array}$ & $\begin{array}{c}\text { Model 2b } \\
\text { HR }(95 \% \text { CI })\end{array}$ \\
\hline All-cause mortality & \multicolumn{2}{|c|}{$\mathrm{n}=6,975$} \\
\hline Number of events (\%) & \multicolumn{2}{|c|}{$738(10.6)$} \\
\hline \multicolumn{3}{|l|}{ Cumulative statin } \\
\hline$\leq 120$ & (referent) & (referent) \\
\hline $121-240$ & $1.39 \quad(1.09-1.76)$ & $1.37 \quad(1.08-1.74)$ \\
\hline $241-360$ & $1.27 \quad(1.01-1.61)$ & $1.25 \quad(0.99-1.58)$ \\
\hline$>360$ & $1.22(1.00-1.48)$ & $1.19 \quad(0.98-1.45)$ \\
\hline Cardiovascular deaths & \multicolumn{2}{|c|}{$\mathrm{n}=6,855$} \\
\hline Number of events (\%) & \multicolumn{2}{|c|}{$196(2.9)$} \\
\hline \multicolumn{3}{|l|}{ Cumulative statin } \\
\hline$\leq 120$ & (referent) & (referent) \\
\hline $121-240$ & $1.13 \quad(0.74-1.71)$ & $1.11 \quad(0.73-1.68)$ \\
\hline $241-360$ & $0.79 \quad(0.50-1.25)$ & $0.75 \quad(0.47-1.18)$ \\
\hline$>360$ & $0.71 \quad(0.50-1.02)$ & $0.66 \quad(0.46-0.94)$ \\
\hline Incident MI & \multicolumn{2}{|c|}{$\mathrm{n}=6,777$} \\
\hline Number of events (\%) & \multicolumn{2}{|c|}{$245(3.6)$} \\
\hline \multicolumn{3}{|l|}{ Cumulative statin } \\
\hline$\leq 120$ & (referent) & (referent) \\
\hline $121-240$ & $0.63 \quad(0.42-0.93)$ & $0.63 \quad(0.43-0.94)$ \\
\hline $241-360$ & $0.64 \quad(0.44-0.94)$ & $0.64 \quad(0.44-0.93)$ \\
\hline$>360$ & $0.37 \quad(0.27-0.51)$ & $0.36 \quad(0.26-0.50)$ \\
\hline Incident stroke & \multicolumn{2}{|c|}{$\mathrm{n}=6,732$} \\
\hline Number of events (\%) & \multicolumn{2}{|c|}{$290(4.3)$} \\
\hline \multicolumn{3}{|l|}{ Cumulative statin } \\
\hline$\leq 120$ & (referent) & (referent) \\
\hline $121-240$ & $0.88 \quad(0.62-1.25)$ & $0.88 \quad(0.62-1.25)$ \\
\hline $241-360$ & $0.67 \quad(0.47-0.97)$ & $0.67 \quad(0.47-0.96)$ \\
\hline$>360$ & $0.48 \quad(0.37-0.65)$ & $0.48 \quad(0.36-0.64)$ \\
\hline Total Costs & Cost Ratios $(95 \% \mathrm{CI})$ & Cost Ratios (95\% CI) \\
\hline \multicolumn{3}{|l|}{ Cumulative statin } \\
\hline$\leq 120$ & (referent) & (referent) \\
\hline $121-240$ & $1.02 \quad(0.95-1.10)$ & $1.02 \quad(0.94-1.10)$ \\
\hline $241-360$ & $0.95 \quad(0.88-1.01)$ & $0.94 \quad(0.88-1.01)$ \\
\hline$>360$ & $1.02 \quad(0.96-1.09)$ & $1.01 \quad(0.95-1.08)$ \\
\hline \multicolumn{3}{|c|}{ 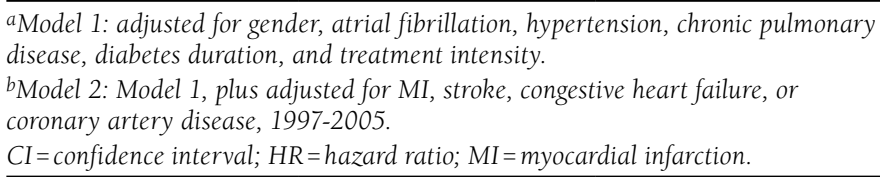 } \\
\hline
\end{tabular}

cumulative statin use ( $\geq 241$ ) had lower cardiovascular mortality, but these associations were statistically significant only for enrollees with the highest cumulative statin use (>360) after controlling for baseline cardiovascular events (hazard ratio $[\mathrm{HR}]=0.66 ; 95 \%$ confidence interval $[\mathrm{CI}]=0.46-0.94)$.

About $3.6 \%$ of enrollees had incident MI, and $4.3 \%$ had incident stroke. Compared with enrollees with no or little cumulative statin use $(\leq 120)$, greater cumulative statin use $(\geq 121)$ was related to lower incidence of MI. Enrollees with the greatest cumulative statin use $(>360)$ had the greatest reduction in risk of incident MI ( $\mathrm{HR}=0.36 ; 95 \% \mathrm{CI}=0.26-0.50)$. In contrast, 
only enrollees with cumulative statin use of 241-360 or $>360$ had lower incidence of stroke ( $\mathrm{HR}=0.67,95 \% \mathrm{CI}=0.47-0.96$; $\mathrm{HR}=0.48,95 \% \mathrm{CI}=0.36-0.64$, respectively). Statin use was unrelated to total costs.

\section{Discussion}

In 2003, Group Health started a pharmacy-based, systemwide outreach to increase the preventive use of statins and ACEIs in enrollees with diabetes. Of the 6,975 Group Health enrollees with no statin history at the start of the outreach in 2003, about half had no or low exposure to statins in 2005. Statin use was generally greater among enrollees with greater risk factors for morbidity and mortality. This pattern may have occurred because Group Health outreach efforts targeted enrollees with cardiovascular risk factors and/or because enrollees with no or few risk factors did not consent, were less adherent in taking statins regularly for prevention, or had statin-induced myopathy. These patterns suggest confounding may influence associations between statin use and health outcomes (i.e., confounding is less likely when everyone in a population receives a preventive intervention). ${ }^{29}$

Among first-time statin users, enrollees with greater statin use at baseline were more likely to have greater use of ACEIs/ ARBs. This finding implies that associations between statin use and health outcomes may be partly a result of ACEI use; in diabetes, ARBs are unrelated to health outcomes, except in patients with diabetes and heart failure. ${ }^{30}$ Although the independent effects of each drug on health outcomes cannot be estimated with this study design, the impact of ACEIs/ARBs on cardiovascular outcomes in this study are likely to be less than statins because use of ACEIs/ARBs at baseline was considerably higher than statins, and the macrovascuslar benefits of ACEIs/ ARBs are more focused in patients with existing coronary disease or heart failure. In addition, the HPS concluded that the cholesterol-lowering benefits of statins are additional to those of other cardioprotective treatments, such as ACEIs and aspirin. ${ }^{3}$

We found that the pharmacy outreach program may have improved cardiovascular outcomes. Compared with enrollees with no or little use of statins, enrollees with greater statin use were less likely to die for cardiovascular reasons (if statin exposure was high) and less likely to have incident MI or stroke. The size of the reduced risks ranged between 33\%-52\%, depending on outcome and length of statin use. These reductions are larger than those found in statin clinical trials, which may be a result of uncontrolled confounding in this observational study design, the added benefits of ACEIs/ARBs, or potentially other medications. In addition, the benefits of prescribing statins for treatment and prevention of cardiovascular disease in a population of patients with diabetes may differ from controlled trials because of lower patient adherence, greater patient heterogeneity, and differences in personal characteristics and lifestyles. ${ }^{31}$
We also found that compared with enrollees with no or little statin use, greater statin use had a nonstatistically significant association with greater all-cause mortality. This finding contrasts with clinical trial evidence that statins reduce the risk of all-cause mortality by $9 \%$ in patients with diabetes. ${ }^{32}$ One potential explanation for this finding is confounding by indication in this observational study: Enrollees with higher statin use also have more observed and probably unobserved risk factors for mortality, and the unobserved risk factors may be producing a spurious association (sicker enrollees take more statins and have a higher probability of death). In addition, the $9 \%$ mortality reduction is from clinical trials comparing statins with placebo, while our study examined the relationships between cumulative statin exposure and outcomes. Another explanation is that the majority of deaths were for noncardiovascular reasons that statins may not influence. Statins may have reduced cardiovascular deaths, allowing patients to live longer and potentially die from other causes. A third potential explanation is that statins caused unintended mortality risks, such as myopathy, liver dysfunction, and renal failure. ${ }^{33}$ Although vascular disease and cancer have similar prevalence as a cause of death in diabetic populations,$^{34}$ the evidence generally does not support an association between statin use and cancer and other disorders. ${ }^{33,35-38}$

Finally, statin use was not associated with total costs. Although increased statin use increased drug costs, total costs did not increase, presumably, because of counteracting reductions in nondrug medical costs as a result of lower medical consumption due to avoided $\mathrm{CV}$ events, which did not require treatment. The cost findings may stimulate the adoption of this program by other health care systems. Given that statins are underused, investing in interventions that deliver statins to entire populations may be more beneficial than investing society's resources in developing new statin therapies. ${ }^{39}$

\section{Limitations}

This study has limitations to consider. Findings are limited to adult primary care populations with diabetes with long-term, continuous health insurance coverage in an integrated delivery system, and with similar patient characteristics. Findings also are limited to integrated systems with pharmacy dispensaries and EMRs with alerts and prepopulated order sets for statins. Because this study relies on secondary data sources, some measures that may explain variation in morbidity and mortality are excluded. Certain types of information were not available on an enrollee level for all years in Group Health databases, such as socioeconomic status, race/ethnicity, tobacco use, or diet. ${ }^{40}$ Data were unavailable for over-the-counter use of aspirin for secondary prevention of atherosclerotic cardiovascular disease. Unmeasured confounding by indication may account for the positive, but statistically nonsignificant, association between statin use and all-cause mortality in this observational study. Other medications not in this model may have had a confounding relationship between statin use and mortality. 


\section{Conclusions}

For patients with diabetes enrolled continuously from 1997 to 2010 in an integrated delivery system, the Group Health pharmacy outreach increased use of statins. Cumulative statin use was greater among enrollees with risk factors for cardiovascular disease. Greater statin use was related to lower risk of cardiovascular death and lower incidence of MI and stroke. Increased statin use was not associated with an increase or decrease in the total costs of medical care.

\section{Authors}

DAVID GREMBOWSKI, PhD, University of Washington School of Public Health, Seattle, Washington. JAMES D. RALSTON, MD, MPH, and MELISSA L. ANDERSON, MS, Group Health Research Institute, Seattle, Washington.

AUTHOR CORRESPONDENCE: David Grembowski, PhD, Department of Health Services, School of Public Health, University of Washington, 1959 N.E. Pacific St., Box 357660, Seattle, WA 981957475. Tel.: 206.616.2921; Fax: 206.543.3964;

E-mail: grem@u.washington.edu.

\section{DISCLOSURES}

This study was funded by Grant No. R21 HS019501 from the Agency for Healthcare Research and Quality (AHRQ) and was conducted as part of the AHRQ announcement Optimizing Prevention and Healthcare Management for the Complex Patient (R21; RFA-HS-10-009). Ralston and Anderson are employees of Group Health and the Group Health Research Institute, which provided the data for this study.

Study concept and design were contributed by Grembowski, Ralston, and Anderson. Anderson assisted with data collection and analysis, and data interpretation was performed by Anderson, along with Grembowski and Ralston. The manuscript was prepared by Grembowski, along with Ralston and Anderson.

\section{ACKNOWLEDGMENTS}

The authors thank Luesa Jordan at Group Health Research Institute, who collected the data for this study.

\section{REFERENCES}

1. Brown LC, Johnson JA, Majumdar SR, Tsuyuki RT, McAlister FA. Evidence of suboptimal management of cardiovascular risk in patients with type 2 diabetes mellitus and symptomatic atherosclerosis. CMAJ. 2004;171(10):1189-92.

2. Heart Protection Study (HPS) Collaborative Group. MRC/BHF Health Protection Study of cholesterol lowering with simvastatin in 20,536 high-risk individuals: a randomized placebo-controlled trial. Lancet. 2002;360(9326):7-22.

3. Heart Protection Study (HPS) Collaborative Group. MRC/BHF Health Protection Study of cholesterol-lowering with simvastatin in 5,963 people with diabetes: a randomized placebo-controlled trial. Lancet. 2003;361(9374):2005-16.
4. Colhoun HM, Betteridge DJ, Durrington PN, et al. Primary prevention of cardiovascular disease with atovastatin in type 2 diabetes in the Collaborative Atorvastatin Diabetes Study (CARDS): multicenter randomised placebo-controlled trial. Lancet. 2004;364(9435):685-96.

5. Mourad JJ, Le Jeune S. Blood pressure control, risk factors and cardiovascular prognosis in patients with diabetes: 30 years of progress. J Hypertens Suppl. 2008;26(3):S7-13.

6. American Diabetes Association. Standards of medical care for patients with diabetes mellitus. Diabetes Care. 2002;25(Suppl 1):S33-49.

7. American Diabetes Association. Standards of medical care for patients with diabetes mellitus. Diabetes Care. 2003;26(Suppl 1):S33-50.

8. American Diabetes Association. Standards of medical care for patients with diabetes mellitus. Diabetes Care. 2004;27(Suppl 1):S15-35.

9. American Diabetes Association. Standards of medical care in diabetes. Diabetes Care. 2005;28(Suppl 1):S4-36.

10. Saydah SH, Fradkin J, Cowie CC. Poor control of risk factors for vascular disease among adults with previously diagnosed diabetes. JAMA. 2004;291(3):335-42.

11. Tricco AC, Ivers NM, Grimshaw JM, et al. Effectiveness of quality improvement strategies on the management of diabetes: a systematic review and meta-analysis. Lancet. 2012;379(9833):2252-61.

12. American Diabetes Association. Standards of medical care in diabetes-2013. Diabetes Care. 2013;36(Suppl 1):S11-66.

13. American Diabetes Association. Strategies for improving care. Diabetes Care. 2016;39(Suppl 1):S6-12.

14. Touchette DR, Shapiro NL. Medication compliance, adherence, and persistence: current status of behavioral and educational interventions to improve outcomes. J Manag Care Pharm. 2008;16(6 Suppl S-d):S2-10. Available at: http://www.amcp.org/data/jmcp/Aug08\%20Suppl\%20D_S2-S10.pdf.

15. Mason JE, England DA, Denton BT, Smith SA, Kurt M, Shah ND. Optimizing statin treatment decisions for diabetes patients in the presence of uncertain future adherence. Med Decis Making. 2012;32(1):154-66.

16. Deyo RA, Cherkin DC, Ciol MA. Adapting a clinical comorbidity index for use with ICD-9-CM administrative databases. J Clin Epidemiol. 1992;45(6):613-19.

17. Coleman SM, Katon W, Lin E, et al. Depression and death in diabetes: 10-year follow-up of all-cause and cause-specific mortality in a diabetic cohort. Psychosomatics. 2013;54(5):428-36.

18. Wahl PM, Rodgers K, Schneeweiss S, et al. Validation of claims-based diagnostic and procedure codes for cardiovascular and gastrointestinal serious adverse events in a commercially-insured population. Pharmacoepidemiol Drug Saf. 2010;19(6):596-603.

19. Kiyota Y, Schneeweiss S, Glynn RJ, Cannuscio CC, Avorn J, Solomon DH Accuracy of Medicare claims-based diagnosis of acute myocardial infarction: estimating positive predictive value on the basis of review of hospital records. Am Heart J. 2004;148(1):99-104.

20. Young B, Lin E, von Korff M, et al. Diabetes Complications Severity Index (DCSI) and risk of mortality, hospitalization and health care utilization. Am J Manag Care. 2008;14(1):15-23.

21. WHO Collaborating Centre for Drug Statistics Methodology. International language for drug utilization research. May 19, 2016. Available at: http:// www.whocc.no/. Accessed July 13, 2016.

22. Jernberg T, Johanson P, Held C, Svennblad B, Lindback J, Wallentin L; SWEDEHEART/RIKS-HIA. Association between adoption of evidence-based treatment and survival for patients with ST-elevation myocardial infarction. JAMA. 2011;305(16):1677-84.

23. Grembowski D, Ralston J, Anderson M. Hemoglobin Alc, comorbid conditions, and all-cause mortality in older patients with diabetes: a retrospective 9-year cohort study. Diabetes Res Clin Pract. 2014;106(2):373-82. 
24. Remington PL, Brownson RC, Wegner MV, eds. Chronic Disease Epidemiology and Control. 3rd ed. Washington, DC: American Public Health Association; 2010.

25. Lawes CM, Thornley S, Young R, et al. Statin use in COPD is associated with a reduction in mortality: a national cohort study. Prim Care Respir J. 2012;21(1):35-40.

26. American Diabetes Association. Standards of medical care in diabetes-2012. Diabetes Care. 2012;35(Suppl 1):S11-63.

27. Stockl KM, Tjioe D, Gong S, Stroup J, Harada AS, Lew HC. Effect of an intervention to increase statin use in Medicare members who qualified for a medication therapy management program. J Manag Care Pharm. 2008;14(6):532-40. Available at: http://www.jmcp.org/doi/10.18553/ jmcp.2008.14.6.532.

28. Casagrande SS, Fradkin JE, Saydah SH, Rust KF, Cowie CC. The prevalence of meeting Alc, blood pressure, and LDL goals among people with diabetes, 1988-2010. Diabetes Care. 2013;36(8):2271-79.

29. Strom BL. Pharmacoepidemiology. New York: John Wiley \& Sons; 2005.

30. Cheng J, Zhang W, Zhang X, et al. Effect of angiotensin-converting enzyme inhibitors and angiotensin II receptor blockers on all-cause mortality, cardiovascular deaths, and cardiovascular events in patients with diabetes mellitus: a meta-analysis. JAMA Intern Med. 2014;174(5):773-85.

31. Grabowski DC, Lakdawalla DN, Goldman DP, et al. The social value resulting from use of statins warrants steps to improve adherence and broaden treatment. Health Aff (Millwood). 2012;31(10):2276-85.

32. Goldfine A. Statins: is it really time to reassess benefits and risks? N Engl J Med. 2012;366(19):1752-55.

33. Hippisley-Cox J, Coupland C. Unintended effects of statins in men and women in England and Wales: a population-based cohort study using the QResearch database. BMJ. 2010;340:c2197.

34. The Emerging Risk Factors Collaboration, Seshasai SR, Kaptoge S, et al. Diabetes mellitus, fasting glucose, and risk of cause-specific death. N Engl J Med. 2011;364(9):829-41.
35. Kohli P, Cannon CP. Statins and safety: can we finally be reassured? Lancet. 2011;378(9808):1980-81.

36. Lutski M, Shalev V, Porath A, Chodick G. Continuation with statin therapy and the risk of primary cancer: a population-based study. Prev Chronic Dis. 2012;9:E137.

37. Finegold JA, Manistry CH, Goldacre B, Barron AJ, Francis DP. What proportion of symptomatic side effects in patients taking statins are genuinely caused by the drug? Systematic review of randomized placebo-controlled trials to aid individual patient choice. Eur J Prev Cardiol. 2014;21(4):464-74.

38. Taylor FC, Huffman M, Ebraham S. Statin therapy for primary prevention of cardiovascular disease. JAMA. 2013;310(22):2451-52.

39. Woolf SH, Johnson RE. The break-even point: when medical advances are less important than improving the fidelity with which they are delivered. Ann Fam Med. 2005;3(6):545-52.

40. McEwen LN, Kim C, Karter AJ, et al. Risk factors for mortality among patients with diabetes: the Translating Research Into Action for Diabetes (TRIAD) Study. Diabetes Care. 2007;30(7):1736-41.

41. Beth Smith ME, Lee NJ, Haney E, Carson S. Drug class review: HMG-CoA reductase inhibitors (statins) and fixed-dose combination products containing a statin. Update 5. Oregon Health \& Science University. November 2009. Available at: http://library.state.or.us/repository/2012/201205010950472/index.pdf. Accessed June 29, 2016.

42. University of Michigan Health System. Screening and management of lipids. UMHS Lipid Therapy Guideline. May 2014. Available at: http:// www.med.umich.edu/linfo/FHP/practiceguides/lipids/lipidsupdate.pdf and https://wiki.umms.med.umich.edu/download/attachments/90738010/ Statins.pdf?version=1. Accessed June 29, 2016.

43. Jones PH, Davidson MH, Stein EA, et al. Comparison of the efficacy and safety of rosuvastatin versus atorvastatin, simvastatin, and pravastatin across doses (STELLAR Trial). Am J Cardiol. 2003;92(2):152-60. 